Review

\title{
Searching for New Molecular Targets for Oral Squamous Cell Carcinoma with a View to Clinical Implementation of Precision Medicine
}

\author{
Tomonori Sasahira ${ }^{1, *(D)}$, Miyako Kurihara-Shimomura ${ }^{2}$, Yudai Shimojjukoku ${ }^{1}$, Kaori Shima ${ }^{1}$ \\ and Tadaaki Kirita ${ }^{2}$ (D)
}

1 Department of Molecular Oral Pathology and Oncology, Field of Oncology, Graduate School of Medical and Dental Sciences, Kagoshima University, Kagoshima 890-8544, Japan; yu-1059@d1.dent.kagoshima-u.ac.jp (Y.S.); kshima@dent.kagoshima-u.ac.jp (K.S.)

2 Department of Oral and Maxillofacial Surgery, Nara Medical University, Kashihara 634-8521, Japan; miyako@naramed-u.ac.jp (M.K.-S.); tkirita@naramed-u.ac.jp (T.K.)

* Correspondence: sasa33@dent.kagoshima-u.ac.jp

check for updates

Citation: Sasahira, T.;

Kurihara-Shimomura, M.; Shimojjukoku, Y.; Shima, K.; Kirita, T. Searching for New Molecular Targets for Oral Squamous Cell Carcinoma with a View to Clinical Implementation of Precision Medicine. J. Pers. Med. 2022, 12, 413 https://doi.org/10.3390/jpm12030413 Academic Editor: Tsuyoshi Sugiura

Received: 7 February 2022

Accepted: 3 March 2022

Published: 7 March 2022

Publisher's Note: MDPI stays neutral with regard to jurisdictional claims in published maps and institutional affiliations.

Copyright: (C) 2022 by the authors. Licensee MDPI, Basel, Switzerland. This article is an open access article distributed under the terms and conditions of the Creative Commons Attribution (CC BY) license (https:// creativecommons.org/licenses/by/ $4.0 /)$.

\begin{abstract}
Head and neck cancer, including oral squamous cell carcinoma (OSCC), is the eighth most common malignancy globally and is characterized by local invasiveness and high nodal metastatic potential. The OSCC incidence is also increasing, and the number of deaths is also rising steadily in Japan. The development of molecular markers to eradicate OSCC is an urgent issue for humankind. The increase in OSCC despite the declining smoking rate may be due to several viral infections through various sexual activities and the involvement of previously unfocused carcinogens, and genetic alterations in individual patients are considered to be more complicated. Given this situation, it is difficult to combat OSCC with conventional radiotherapy and chemotherapy using cell-killing anticancer drugs alone, and the development of precision medicine, which aims to provide tailormade medicine based on the genetic background of each patient, is gaining attention. In this review article, the current status of the comprehensive search for driver genes and biomarkers in OSCC will be briefly described, and some of the candidates for novel markers of OSCC that were found will be outlined.
\end{abstract}

Keywords: oral squamous cell carcinoma; precision medicine; biomarker

\section{Introduction}

Globally, oral squamous cell carcinoma (OSCC), including lip cancer, accounts for 377,713 new diagnoses and 177,757 deaths in 2020 , approximately $2 \%$ of all malignancies and $1.8 \%$ of cancer deaths [1]. In 2022, it is estimated that approximately 54,000 new patients will be diagnosed with OSCC in the United States, and 11,230 individuals will die of this disease [2]. OSCC is usually detected at an advanced stage, reflecting that it is an aggressive tumor with high local invasiveness and metastatic potential. For these reasons, the overall 5-year survival rate is $<50 \%$ and has hardly improved over the past decades, despite significant advances in molecular biology and cancer treatment [3]. Recently, the number of secondary cancers seen in long-term survivors of hematopoietic stem cell transplantation has been increasing and becoming a problem, and oral cancer is the most frequent among them [4]. Additionally, OSCC often causes postoperative difficulty in chewing and swallowing, dysarthria, and loss of facial aesthetics, leading to a significant decrease in the patient's quality of life (QOL). Therefore, the early detection and diagnosis of cancer is an urgent issue to improve the postoperative QOL of patients by suppressing OSCC and maintaining several oral functions and aesthetics.

Recently, Hanahan and Weinberg [5] proposed the concept of "Hallmarks of Cancer" that cancer acquires the following characteristics during its development and progression: 
(1) maintenance of growth signals, (2) evasion of growth inhibition, (3) resistance to cell death, (4) immortalization of cells, (5) invasion and metastasis, (6) angiogenesis, (7) evasion of tumor immunity, (8) abnormal energy metabolism, (9) tumor-promoting inflammation, and (10) genomic destabilization and mutation. It is generally accepted that OSCC arises from multiple genetic alterations, including deletions, insertions, point mutations, promoter methylation, gene amplification of oncogenes, inactivate tumor suppressor genes, and so on through exposure to chronic stimuli, such as alcohol consumption, smoking, certain viral infections, inflammation, ill-fitting dentures, and prostheses, as well as sharp edges of teeth because of dental caries, and these changes are acquired concurrently or heterogeneously. Among the "Hallmarks of Cancer", invasion and metastasis are major cancer recurrence and treatment failure factors. Cancer invasion and metastasis require a series of steps: reduction in cancer cell adhesion, acquisition of motility, progression to the stroma, vascular invasion, extravasation, and proliferation at the site of metastasis [6]. Therefore, cancer should theoretically be controllable by inhibiting any of these cascades. However, identifying therapeutic targets to inhibit the invasion and metastasis of OSCC is very difficult owing to multiple genetic alterations that occur in this continuous process and the complex relationships between the individual abnormalities.

Today, the development of diagnostic and therapeutic agents and the elucidation of the molecular pathogenesis of cancer are being actively pursued, driven in large part by remarkable advances in molecular biology and genomics. The main molecular target drugs available for oral cancer in Japan are cetuximab, a mouse monoclonal antibody targeting epidermal growth factor receptor (EGFR), and nivolumab, an immune checkpoint inhibitor that blocks the programmed death-1 (PD-1) and PD-ligand 1 (PD-L1) pathways [7]. Additionally, pembrolizumab is used to treat unresectable/metastatic OSCC with microsatellite instability-high (MSI-H) [8]. However, due to the rarity of MSI-H in oral cancer [9], the indication for pembrolizumab is very limited. Recently, entrectinib, which targets the neurotrophic receptor tyrosine kinase (NTRK) fusion gene, has been used across organs [10], but compared to other cancers, there are very few molecular targeted drugs available for OSCC. Thus, even with the progress made in molecular biology and genomic medicine, it is still difficult to say that there are useful diagnostic and therapeutic markers for OSCC, and identifying such markers is an urgent issue. In the future, the development of safe, effective, and highly useful drugs and diagnostics without adverse events, the establishment of biomarkers and overcoming drug resistance in oral cancer are urgently needed.

\section{Current Status of NGS Analysis in OSCC}

The development of next-generation sequencing (NGS) has enabled high-throughput analyses such as whole-genome mutation analysis, multiple target gene profiling, and comparison of tumor and normal samples. Compared with conventional polymerase chain reaction (PCR)-based genetic analysis and microarrays, NGS can provide much more detailed information in a shorter period. Of the "personalized medicine", meaning medical treatment that selects the best treatment based on an individual's genetic mutation and genome information, "precision medicine" is particularly concerned with finding abnormalities in biomarkers and therapeutic drugs in the vast amount of data obtained by NGS [11]. From June 2019, cancer genome profiling (CGP) test using the NGS-based FoundationOne ${ }^{\circledR}$ companion diagnostic (F1CDx; Foundation Medicine, Inc, Cambridge, MA, USA) tests and OncoGuide ${ }^{\mathrm{TM}}$ NCC Oncopanel System (Sysmex Corp, Kobe, Japan) will be covered by insurance in Japan for patients with solid tumors who have not received or completed standard treatment [12]. The CGP test is used to determine the optimal molecular targeted drugs that match the genetic mutations and genomic information of each patient, and its widespread use is expected to accelerate the development of precision medicine in the future. However, most of the targeted drugs that match the genetic abnormality are administered through participation in clinical trials or off-label use, and only a few percent to a dozen percent of patients who undergo CGP testing receive treatment based on the detected genetic mutation $[13,14]$. Although there are still many problems to be solved 
at this point, it is undeniable that this is a revolutionary test for finding new treatment methods, and it is expected to bring great benefits to cancer patients who have run out of options.

Recently, a report on large-scale analysis of genetic abnormalities in head and neck SCC (HNSCC), including OSCC, using NGS was published [15]. The outline of the genetic abnormality is summarized in Figure 1. According to the report, cyclin-dependent kinase inhibitor 2A (CDKN2A), cyclin D1 (CCND1), EGFR, fibroblast growth factor receptor 1 (FGFR1), Fas-associated via death domain (FADD), FAT atypical cadherin 1 (FAT1), tumor protein 53 (TP53) caspase-8 (CASP8), Notch receptor 1 (NOTCH1), ajuba LIM protein $(A J U B A)$, and MYC proto-oncogene $(M Y C)$ genotypes are the most important in human papilloma virus (HPV)-negative HNSCC. Among them, CASP 8 mutation was observed in $92 \%$ of OSCC, and cases with HRas Proto-Oncogene, GTPase (HRAS) and phosphatidylinositol4,5-bisphosphate 3-bisphosphate catalytic subunit alpha (PIK3CA) activation, NOTCH1 inactivation, and wild-type TP53 have particularly had a favorable prognosis. Regarding the association with smoking, which is a major cause of oral carcinogenesis, TP53 mutation, CDKN2A loss of function, amplification of $3 q$ and $11 q$, and alterations of oxidative stress-related genes Kelch-like ECH-associated protein 1 (KEAP1), nuclear factor, erythroid 2 like 2 (NFE2L2), and cullin 3 (CUL3) has been clarified. This report also suggests that a single driver mutation does not cause HPV-positive group, although they tend to show TNF receptor-associated factor 3 (TRAF3) inactivation and amplification of FGFR3 and E2F1, and fewer mutations in TP53, CDKN2A, and nuclear receptor binding SET domain protein 1 (NSD1).

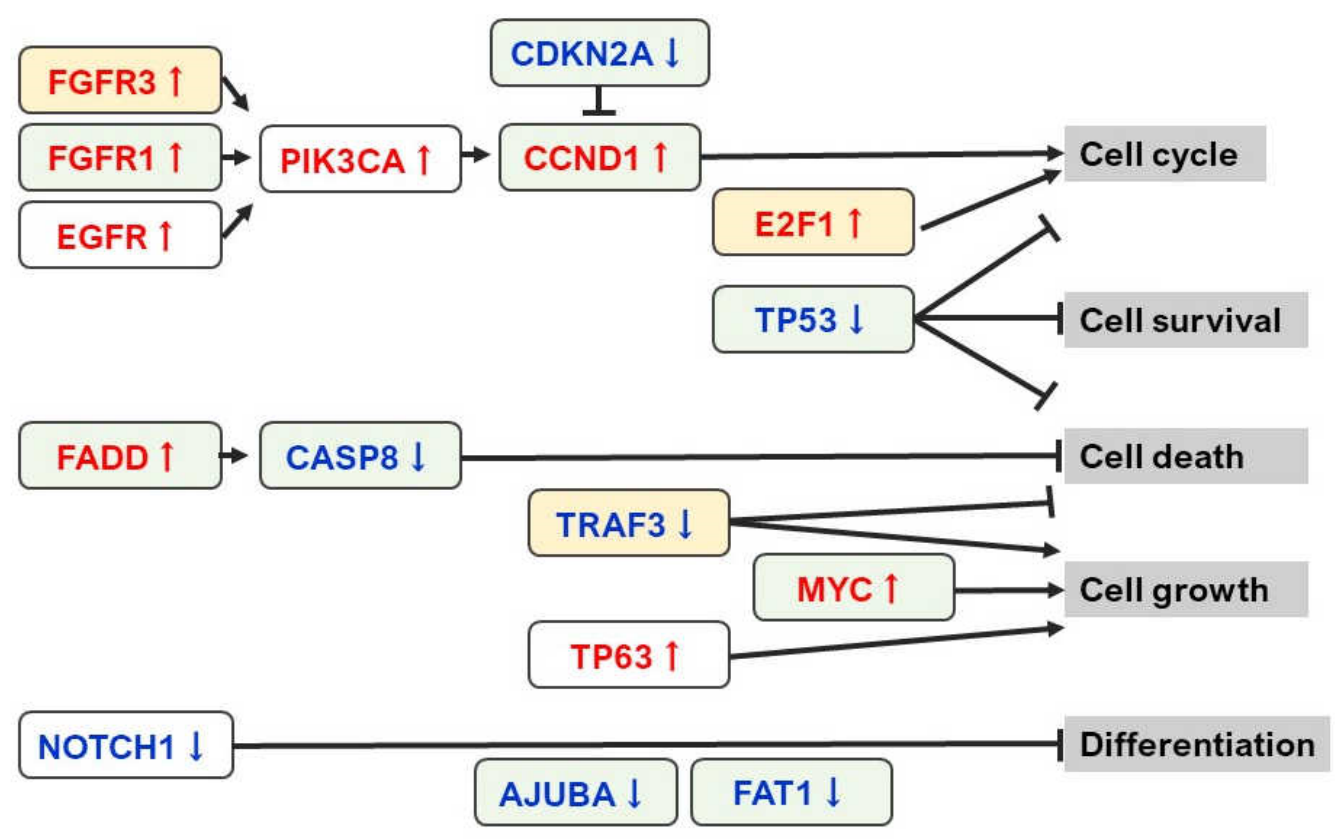

CUL3 $\downarrow$

KEAP1 $\downarrow$ NFE2L2 $\uparrow$

Oxidative damage

Figure 1. Shema of signaling pathways highly prevalent in head and neck cancer. The green and yellow columns represent HPV-negative and HPV-positive cancer predominance, respectively. Figure in [15] was modified.

As shown in Table 1, HPV-positive oropharyngeal carcinoma (including OSCC) has different biological characteristics from the usual OSCC [16]. Although radiation therapy with cetuximab was expected to be effective in HPV-related oropharyngeal cancer [17], 
recent reports have revealed that the efficacy of this combination therapy is poor, and the combination of cisplatin and radiation therapy is the current standard treatment $[18,19]$.

Table 1. Biological features of head and neck cancer associated with HPV infection.

\begin{tabular}{lll}
\hline & \multicolumn{1}{c}{ HPV-Positive Cancer } & \multicolumn{1}{c}{ HPV-Negative Cancer } \\
\hline Risk factor & Oral sex & Smoking, alcohol abuse \\
Age & Under 60 years & Above 60 years \\
Surrogate marker & p16 & p53 \\
Susceptible site & Oropharynx & Various sites \\
Outcome & Good & Bad \\
\hline
\end{tabular}

At present, attempts to classify cancers into molecular subtypes based on gene expression profiles are being made, and HNSCC has been classified into basal (BA), atypical, mesenchymal, and classical molecular subtypes based on differences in the status of the KEAP1 and NFE2L2 oxidative stress pathway, expression of the lineage markers SRY-box transcription factor 2 (SOX2) and TP63, and activation of the oncogenes PIK3CA and EGFR (Table 2) [20]. Keck et al. [21] have also reported that HNSCC is classified into five subtypes: BA, CL-HPV, CL-non-HPV, inflamed/mesenchymal subtypes (IMS)-HPV, and IMS-non-HPV. According to their study, the IMS subtype is involved in tumor immunity, and the two HPV subtypes are characterized by low expression of EGFR/HER ligands and no copy number events. The BA subtype, on the other hand, is characterized by a prominent EGFR/HER signaling phenotype, HPV negativity, and strong hypoxic differentiation. In addition, transcriptome profiling of approximately 6000 single cells from 18 HNSCC patients demonstrated that the expression of signatures related to cell cycle, stress, hypoxia, epithelial differentiation, and partial epithelial-mesenchymal transition (p-EMT) are important in malignant cells, and p-EMT, in particular, is a predictor of lymph node metastasis and malignancy in cancer [22]. Huang et al. [23] also classified HNSCC with lymph node metastasis into molecular subtypes of Group 1 (immune subtype with enriched pathways, including allograft rejection, T-cell receptor signaling pathway, and chemokine receptor signaling), Group 2 (invasive subtype with enriched pathways, including epithelial-mesenchymal transition, apical junction, angiogenesis, hypoxia, extracellular matrix receptor interactions, regulation of the actin cytoskeleton, and focal adhesion), and Group 3 (metabolic/proliferative subtype with enriched pathways, including MYC targets, basal transcription factors, and mismatch repair) based on comprehensive mRNA expression profiles. Among these subtypes, Group 2 has the worst overall survival rate and disease-free survival rate, as well as the lowest local control rate of cancer. Identifying molecular subtypes of OSCC based on such comprehensive analysis will greatly contribute to the selection and development of optimal cancer therapeutics agents for individuals.

Table 2. Biological characteristics of head and neck cancer by molecular subtype.

\begin{tabular}{|c|c|c|c|c|}
\hline & Basal & Mesenchymal & Atypical & Classical \\
\hline Differentiation & Well, moderate & Moderate, poor & Moderate & Moderate, poor \\
\hline Predominant site & Oral cavity & Oral cavity & Oropharynx & Larynx \\
\hline $\begin{array}{l}\text { Lymph node } \\
\text { metastability }\end{array}$ & Low & Moderate & High & Low \\
\hline $7 p$ gain & Yes & Yes & No & Yes \\
\hline CDKN2A loss & Occasionally & Rarely & Rarely & Frequently \\
\hline SOX2 expression & Low & Low & High & High \\
\hline TP63 expression & High & Moderate & Moderate & Moderate \\
\hline
\end{tabular}

\section{Tumor Biomarker and Liquid Biopsy}

Although there have been many studies on tumor biomarkers, practical and useful ones for OSCC have not yet been established. Despite the importance of postoperative 
adjuvant therapy along with surgery to treat advanced OSCC, conventional methods, such as chemotherapy using cell-killing anticancer drugs, radiation therapy, and combination therapy of both still remain the mainstream of adjuvant therapy for OSCC. These conventional methods also inevitably cause significant harm to normal cells. The current situation is that there are almost no definitive treatment options. In the coming era, it is expected that the development of clinical tests (diagnostic markers) based on gene and protein expression and mutation profiles, prediction of metastatic potential and prognosis will be actively promoted. A comprehensive analysis of genomic data is also useful for molecular biological cancer diagnosis and subclassification. Furthermore, the accumulation of genetic information related to carcinogenesis and cancer progression will directly lead to the development of effective new drugs by clarifying mutated genes and the signaling pathways altered by them.

Tumor biomarkers are divided into several types: screening markers, early diagnostic markers, staging markers, prognostic markers, and predictive and monitoring markers [24]. It has been reported that tumor biomarkers must meet the following conditions. (1) the change must be objectively quantifiable, (2) it must be possible to measure with a small amount of sample, (3) the change must occur in cancerous tissue, not in normal tissue, and (4) it must be detected in the early stages of cancer development [25]. Presently, attempts at diagnosis by liquid biopsy using blood, urine, saliva, pleural fluid, ascites, etc. have been gaining attention. The information obtained by liquid biopsy reflects changes throughout the tumor and has the advantage of being less susceptible to tumor heterogeneity compared to tissue biopsy. It is also less invasive, results can be obtained quickly, and biomarker monitoring is possible [26]. The main targets for biomarker discovery by liquid biopsy using blood are cell-free DNA (cfDNA), circulating tumor cells (CTC), and microRNA (miR, miRNA), which are shown below.

\section{1. $c f D N A$}

Circulating cfDNA is released into the blood due to cell apoptosis or necrosis, and those derived from tumor cells are especially called circulating tumor DNA (ctDNA) [27]. Since cfDNA is fragmented by endonuclease, the average cfDNA concentration in the blood of healthy people is about 10-15 $\mathrm{ng} / \mathrm{mL}$, but the blood ctDNA of patients with cancer is often highly concentrated $[27,28]$. The major clinical application of ctDNA analysis is the identification of new mutations by gene profiling and selecting effective molecular targeted drugs [29]. Previous reports have shown that TP53, PIK3CA, CDKN2A, F-box, and WD repeat domain containing 7 (FBXW7), HRAS, NOTCH1, CASP8, and phosphatase and tensin homolog (PTEN) mutations can be detected in plasma ctDNA [15,30]. It was also reported that hypermethylation of short stature homeobox protein 2 (SHOX2) and septin 9 (SEPT9) in ctDNA is observed in 59\% of patients with HNSCC with $96 \%$ specificity [31]. Therefore, ctDNA in blood can be a useful OSCC biomarker.

\subsection{CTC}

CTCs are circulating cells released from tumor tissue into the bloodstream and play a critical role in the formation of metastases [27,32]. Many of the CTCs have the ability to leave the primary tumor lesion by acquiring epithelial-mesenchymal transition (EMT) phenotypes and eventually form new metastases [32]. Previous reports have shown that HNSCC patients with lymph node metastasis have a significantly higher detection rate of CTCs in their blood than those without [33]. Global gene expression analysis by microarray using blood CTC from 36 patients with OSCC has shown that upregulation of CD274 (commonly known as PD-L1), homeobox B9 (HOXB9), and zinc finger protein 813 (ZNF813) and decreased expression of $\mathrm{B}$ cell linker $(B L N K)$ are frequently observed [34]. In relation to treatment, the number of CTCs in the blood has been found to be significantly reduced after chemoradiation therapy in OSCC [35]. It was also shown that HNSCC patients who responded to nivolumab treatment had higher levels of CCND1 expression in their CTCs [36]. Additionally, phosphorylation levels of EGFR are dramatically reduced in the blood CTCs 
of patients with OSCC who responded to cetuximab [37]. In addition, there are reports that the presence of CTCs in HNSCC contributes to prognosis in HNSCC patients [36,38,39], and in particular, patients with CTCs expressing MET have a significantly poorer prognosis [36]. Thereby, clarifying the molecular characterization of CTCs may be useful for predicting the potential for metastasis, successful treatment, and clinical outcome in OSCC. Since recent studies have revealed that CTCs have different characteristics from both primary tumors and metastatic tumors [38]. CTCs are expected to be applied to many fields, including understanding metastatic mechanisms, searching for new therapeutic targets, and developing personalized medicine. However, reliable CTC capture and improved single-cell sequencing are essential for clinical implementation, and further system development is expected [32].

\section{3. $\operatorname{miRNA}$}

Exosomes are vesicles secreted by cells and contain mRNA, genomic DNA, cDNA, miRNA, etc. It has long been believed that gene functions are brought about by the proteins they code, and non-coding RNA (ncRNA), which do not code for specific proteins, were not considered important as "junk in the genome". However, it has become clear that ncRNA also plays an important role, especially miRNA, a small single-stranded RNA of approximately 18-25 nucleotides that negatively regulate gene expression by binding to the $3^{\prime}$ untranslated region (UTR) of target genes with complementary sequences [39]. The biosynthetic process of the mature miRNA can be explained as follows: Primary miRNA (pri-miRNA) is converted to precursor miRNA (pre-miRNA) by RNase Drosha and DiGeorge syndrome critical region gene 8 (DCRG8) in the nucleus. The pre-miRNA is transported into the cytoplasm by exportin 5 and processed into mature microRNA by RNase Dicer. Mature miRNA regulates mRNA expression of target genes after being incorporated into the RNA-inducible silencing complex (RISC) [6]. In recent studies using miRNA arrays, upregulation of $m i R-19 a, m i R-512-3 p, m i R-27 b, m i R-20 a, m i R-28-3 p, m i R-$ 200c, miR-151-3p, miR-223, and miR-20b and decreased expression of miR-22, miR-370, $m i R-139-5 p$, let-7e, $m i R-145-3 p$, and $m i R-30 c$ have been confirmed in exosomes of patients with OSCC [40]. Additionally, plasma levels of $m i R-31$ and $m i R-184$ have decreased after tumor resection and are expected to be useful markers of disease progression [28,41,42]. MiRNA molecules in exosomes can be a minimally invasive test marker, and it is necessary to further clarify their functional significance in the future.

\section{Candidate for Novel Secretory Molecular Markers in OSCC}

Despite NGS development and the search for OSCC molecular markers, as aforementioned, there are still numerous issues that need to be addressed. The molecular classification of OSCC and identification of driver genes are extremely difficult. Additionally, there are still no biomarkers or molecularly targeted drug candidates to be used as a decisive factor in OSCC. Several candidate molecules involved in the characterization of OSCC were revealed. Sections 3 and 4 outline the recently identified new markers separately for secretory and non-secretory components, respectively.

\subsection{TANGO and Related Molecules (MUC20 and SRPX2)}

\subsubsection{TANGO}

Members of the melanoma inhibitory activity $(M I A)$ gene family are secreted proteins that comprise $M I A, M I A 2$, transport and Golgi organization protein 1 (TANGO), and otoraplin (OTOR) and share 34-45\% amino acid homology and 47-59\% cDNA sequence homology and possess a highly conserved Src homology 3 (SH3)-like domain and hydrophobic $\mathrm{N}$-terminal secretory signal sequence [43]. Among them, TANGO interacts with integrin CD11c/CD18 and influences premonocytic cells by reducing attachment and promoting migration [44]. TANGO is also a tumor suppressor in malignant melanoma [43] and colorectal and hepatocellular carcinoma [42]. Conversely, it was found that TANGO promoted cell proliferation and invasion and inhibited apoptosis in OSCC cells [45]. Gene expression 
levels of TANGO were higher in almost all OSCC cases and cells than in the normal oral mucosa and other cancer cells and specimens. Additionally, TANGO regulated the adhesion of OSCC cells to primary human umbilical vein endothelial cells (HUVEC) and primary human dermal lymphatic microvascular endothelial cells (HDLMVEC) and transendothelial migration and tube formation of endothelial cells by activating platelet-derived growth factor beta polypeptide (PDGFB) and neuropilin 2 (NRP2). Upon immunostaining with OSCC material, the positive rate of TANGO was $35.1 \%(60 / 171)$, and its expression was associated with $\mathrm{T}$ stage, clinical stage, lymph node metastasis, microvessel density (MVD), lymphovessel density (LVD), and expression of PDGFB and NRP2. Additionally, cases expressing TANGO had a significantly poorer prognosis. TANGO may be a new biomarker of angiogenesis and lymphangiogenesis in OSCC.

TANGO and other members of the MIA gene family are secreted proteins that are detected at high levels in the serum and saliva of oral cancer patients, and MUC20 is probably secreted and detected in the same way. In actual clinical practice, measuring the secretion of these factors in saliva will have great potential for application as a minimally invasive tumor marker. For more information on the MIA gene family in OSCC, please refer to my previous review [46].

\subsubsection{MUC20}

Since differences in downstream signaling were thought to be the reason why TANGO, a tumor suppressor in other cancers, functions in a pro-tumor manner in OSCC, microarray analysis was performed using multiple OSCC cells, and mucin 20 (MUC20) was identified as a new molecule located downstream of TANGO [47]. MUC20 is a molecule involved in mucin production and has been reported to play a tumor-promoting role in gastrointestinal cancer $[48,49]$ and gynecological cancer [50]. Expression levels of MUC20 were increased or decreased in OSCC cells treated with TANGO gene transfer or knockdown, respectively. Furthermore, expression levels of MUC20 were decreased or restored by TANGO antibody treatment or recombinant protein addition to OSCC cells, respectively. These results indicate that TANGO activates MUC20TANGO. In MUC20-transfected cell lines, interaction with TANGO enhances proliferative potential through increased c-met phosphorylation and contributes to invasive potential by decreasing the secretion of E-cadherin, which is involved in cell adhesion, and increasing the secretion of matrix metalloproteinase-2 (MMP2), which promotes stromal destruction. MUC20 also enhanced the migration, proliferation, and luminal formation of HUVEC and HDLMVEC via VEGF-A and VEGF-C, as well as the adhesion between OSCC and endothelial cells. Real-time reverse transcription-polymerase chain reaction (RT-PCR) analysis using 30 frozen specimens of OSCC showed higher gene expression levels of MUC20 than the normal oral mucosa. In immunohistochemistry of formalin-fixed paraffin-embedded (FFPE) specimens of OSCC cases, MUC20 expression $(64 / 213 ; 30.1 \%)$ was significantly correlated with clinical stage, lymph node metastasis, MVD, LVD, and poor prognosis. These results suggest that MUC20, whose expression is regulated by TANGO, is involved in OSCC progression.

In esophageal SCC, MUC20 has been reported to be involved in the acquisition of paclitaxel resistance [51]. Paclitaxel is an anticancer drug commonly used in OSCC, and MUC may be useful as a biomarker to predict anticancer drug resistance in OSCC. Additionally, since MUC20 is a secreted protein, it is expected to be clinically applicable as a minimally invasive and monitorable biomarker.

\subsubsection{SPRR1B}

Small proline-rich protein 1B (SPRR1B) is another novel molecule downstream of TANGO in OSCC [47]. SPRR1B is a marker for squamous cell differentiation, and its expression is high in the tongue, skin, and well-differentiated cutaneous and esophageal SCC [52]. SPRR1B is also associated with squamous metaplasia of the airway epithelium [53], and its expression is lower in gastric cancer [54] and lung adenocarcinoma [55]. In clinical samples, expression levels of SPRR1B were significantly higher in adjacent normal mu- 
cosa than in OSCC tissues. Moreover, SPRR1B immunopositivity was $71.6 \%(88 / 123)$ in well-differentiated OSCC but 53.3\% (48/90) in those with moderate to poorly differentiated OSCC. In an in vitro study using OSCC cells, well-differentiated HSC4 cells expressed higher levels of SPRR1B than poorly differentiated HSC3 cells. It was also found that the interaction of TANGO with SPRR1B increased the expression of involucrin and keratin 1 , which are differentiation markers of keratinocytes. It has been reported that MAPK p38 plays an important role in keratinocyte proliferation [56], and it was also found that $S P R R 1 B$ induces MAPK $\mathrm{p} 38$ proliferation and promotes proliferation of well-differentiated OSCC cells. These results suggest that SPRR1B is involved in OSCC cell differentiation. The schema of TANGO-related signals is shown in Figure 2.

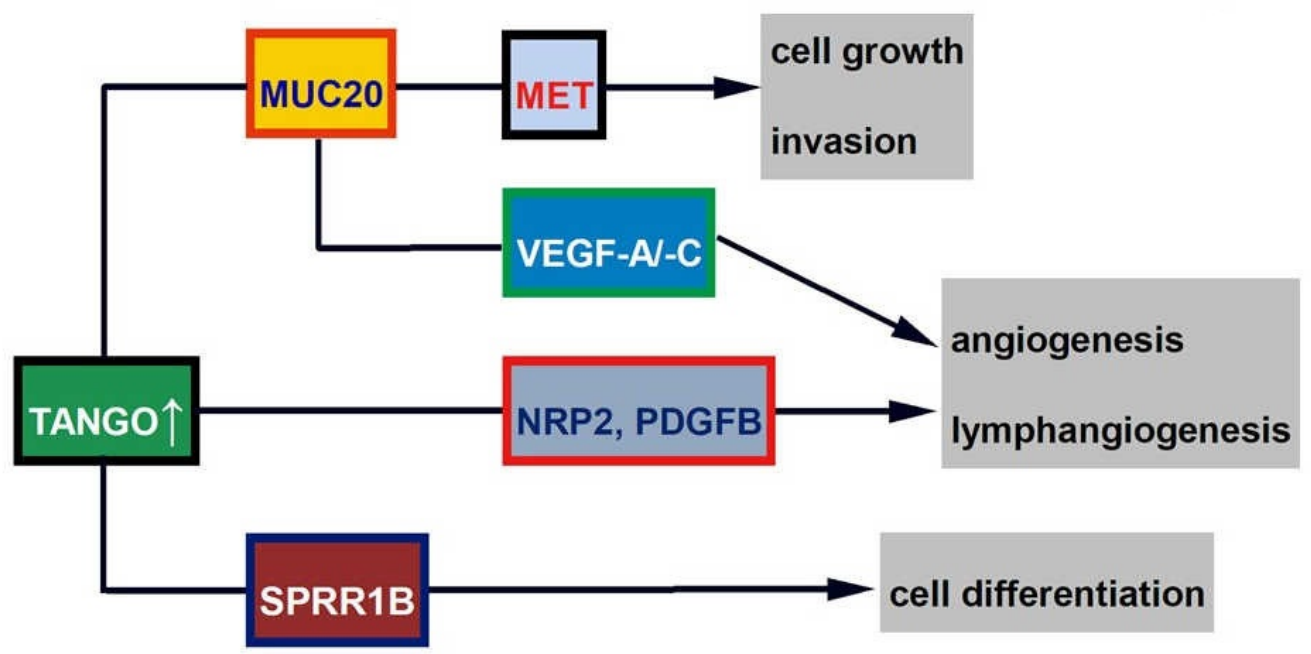

Figure 2. Shema of TANGO-related signal.

Since involucrin and keratin 1 are thought to be the molecules involved in the final differentiation of keratinocytes [57], SPRR1B may contribute to the final determination of OSCC differentiation in the presence of TANGO. In poorly differentiated OSCC, $S P R R 1 B$ transfection may reduce malignancy by stimulating the proliferation of mature keratinocytes through MAPK p38 phosphorylation and increasing the degree of differentiation. The usefulness of SPRR1B as a therapeutic target in OSCC needs to be further investigated.

\subsection{LEMD1 and Ralated Molecules (SRPX2 and SERPINE2)}

\subsubsection{LEMD1}

LEM domain containing 1 (LEMD1) is a type of cancer-testis antigen (CTA) whose expression is highly restricted to testicular germ cells and has been reported to be highly expressed in colorectal cancer [58]. In immunohistochemistry using 289 OSCC specimens, the LEMD1 positivity rate was 35\% (101/289), and its expression was significantly correlated with tumor progression (T stage and clinical stage) and nodal metastasis [24]. Multivariate analysis using the COX proportional hazards model revealed that LEMD1 expression was an independent poor prognostic factor for OSCC. In vitro studies showed that LEMD1 promoted invasion of OSCC cells, adhesion of OSCC cells to HUVEC and HDLMVEC, and migration and tube formation of endothelial cells. Although further studies are needed, these results indicate that LEMD1 is a novel biomarker for OSCC.

LEMD1 is a CTA. Recently, oncogenic CTA in malignant tumors has been suggested to be useful targets for immunotherapy by activating cytotoxic T lymphocytes [59]. The normalization of LEMD1 may be useful for activating the host immune function, but further in vivo and in vitro studies are required to clarify the possibility of LEMD1-targeted immunotherapy. 


\subsubsection{SRPX2}

Sushi repeat-containing protein X-linked 2 (SRPX2) is a gene involved in the development of the language centers of the brain (Broca's area and Wernicke's area) [60] and has tumor-promoting functions in gastrointestinal cancer [61-63]. SRPX2 was found to be a novel gene related to $L E M D 1$ by a comprehensive gene expression analysis using microarray [64]. As receptors for $S R P X 2$, urokinase plasminogen activator receptor (uPAR) [65] and hepatocyte growth factor (HGF) [61] are known, and it was found that SRPX2 was secreted into the culture supernatant by treating oral cancer cell lines with recombinant proteins of uPAR and HGF. Additionally, cell culture of vascular and lymphatic endothelial cells in supernatants of OSCC cells that highly express SRPX2 increases migration and proliferation, but these effects are attenuated by combined treatment with anti-uPAR and anti-HGF antibodies. Therefore, SRPX2 may be a ligand for UPAR and HGF in OSCC. Notably, SRPX2 is associated with anticancer drug resistance and was closely related to the development of resistance to platinum drugs such as cisplatin and nedaplatin in OSCC cells. The positive rate of SRPX2 in immunostaining of $161 \mathrm{FFPE}$ specimens was $28 \%(45 / 161)$, and SRPX2 was more highly expressed in patients with lymph node metastasis or high MVD or LVD, and those with high SRPX2 expression had a significantly poorer prognosis than those without. Additionally, the expression levels of LEMD1 and SERPINE2 correlated well with each other in real-time RT-PCR using frozen OSCC specimens.

To improve OSCC prognosis, early detection and effective adjuvant therapy after surgery are extremely important. If effective adjuvant therapy can be selected, it will be possible to preserve oral functions (speech, pronunciation, mastication, swallowing, etc.) and maintain facial aesthetics after surgery. However, there are currently no definitive chemotherapy, radiotherapy, or chemoradiotherapy resumes in patients with OSCC. Since $S R P X 2$ is a secreted protein and is resistant to platinum drugs, measuring its secretion levels in saliva may be applied to predict the effect of adjuvant therapy and select appropriate anticancer drugs.

\subsubsection{SERPINE2}

Serpin peptidase inhibitor, clade E, member 2 (SERPINE2), has been reported to be a risk gene involved in OSCC development in genome-wide haplotype analysis [66], but it acts as a tumor suppressor in other cancer types [67-69]. Therefore, its function is not well understood. SERPINE2 is another molecule that the authors found as a LEMD1-related signal using microarray analysis [70]. It was confirmed that knockdown of the SERPINE2 gene in OSCC cells suppressed the expression of SERPINE2 at the protein level and the secretion into the culture supernatant. In 42 OSCC samples, higher levels of SERPINE2 secretion than in normal mucosa were confirmed by ELISA, indicating that SERPINE2 acts as a secreted protein in OSCC. Additionally, the effect of SERPINE2 on angiogenesis was investigated in vitro, and it was found that SERPINE2 induced proliferation, migration, and tube formation of HUVEC and HDLMVEC and promoted the interaction between OSCC and endothelial cells. Furthermore, SERPINE2 enhanced proliferation and invasion ability in OSCC cells. In immunohistochemistry of 167 FFPE specimens, the SERPINE2 expression rate was $38.9 \%$ (65/167), and its expression was correlated with the depth of invasion, MVD, and LVD. Additionally, it was shown to be an independent poor prognostic factor in multivariate analysis. These results suggest that SERPINE2 acts as a vascular/lymphangiogenic factor in oral cancer by exerting its function as a secreted protein. The downstream signal of LEMD1 is shown in Figure 3. 


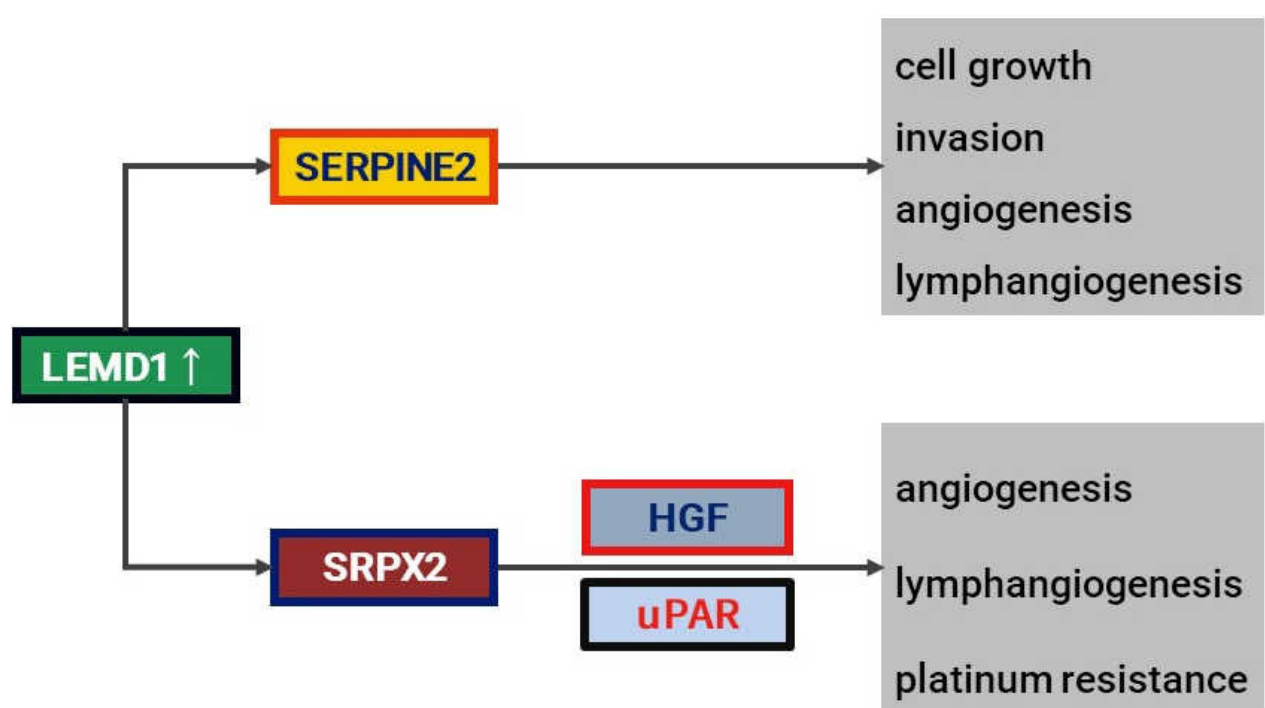

Figure 3. Shema of LEMD1-associated signal.

Tumor blood vessels/lymphatic vessels supply nutrients to cancer, but compared to normal blood and lymphatic vessels, they have an irregular morphology with no pericyte lining and insufficient lumen formation, making it difficult for anticancer drugs to reach the cancer site [71]. In addition, tumor blood vessels continue to produce VEGF family members due to continued hypoxia because of their irregular structure and very poor blood flow. Furthermore, the increased vascular permeability increases the pressure in the tumor stroma, suggesting a vicious cycle that reduces the efficiency of anticancer drug transfer from blood vessels to the tumor [72]. The inhibition of tumor angiogenesis and/or lymphangiogenesis may dramatically reduce cancer progression. Anti-angiogenic drugs are frequently used in cancer types other than OSCC, but unfortunately, there are currently no anti-angiogenic molecular target drugs approved by insurance for OSCC in Japan. Recently, a new concept of anti-angiogenic and/or lymphangiogenic therapy has been proposed to normalize abnormal blood and lymphatic vessels to improve local delivery and retention of anticancer drugs $[73,74]$. The possibility of anti-angiogenic/lymphangiogenic therapy targeting SERPINE2 is also expected, and further investigation is needed in the future.

\section{Candidate for New Non-Secretory Markers in OSCC}

\subsection{PXDN}

Cancer cells suppress mitochondrial activity, shift glucose metabolism primarily to glycolysis, and produce lactate and adenosine triphosphate (ATP) even in the presence of oxygen (Warburg effect). These metabolic changes are thought to induce the generation of reactive oxygen species (ROS) and promote cancer progression [75]. Recent reports suggest that peroxidasin $(P X D N)$ promotes tumorigenesis and the survival of prostate cancer cells by inhibiting oxidative stress through the removal of ROS and inducing apoptosis through the Warburg effect [76]. PXDN overexpression was observed in various malignancies [77,78]. In OSCC, PXDN mRNA upregulation was confirmed in 42 of 111 cases $(37.8 \%)$ and was also expressed at higher levels in cases with lymph node metastasis and diffuse invasion patterns. Patients with high PXDN expression had a significantly poorer prognosis, and a high PXDN expression was an independent poor prognostic factor in multivariate analysis. Furthermore, expression levels of PXDN in OSCC were proportional to lactate and ATP production and inversely correlated with ROS production but not with the activation state of mitochondria. These results suggest that PXDN might promote OSCC by affecting cancer cell metabolism [79].

Generally, the Warburg effect on cancer cells is believed to promote cancer invasion and metastasis [75]. Conversely, the Warburg effect acts in a tumor-suppressive manner in 
the early stages of carcinogenesis [80]. Although there are many unanswered questions about the Warburg effect in cancer, these results suggest that the Warburg effect induced by PXDN is cancer-promoting. Since ROS produced by defective mitochondria promotes cancer development and progression, reducing oxidative stress was considered a potential means of cancer prevention and treatment [81]. However, there are reports that antioxidants promote the development and metastasis of cancer [82,83]. Furthermore, it has been reported that the accumulation of excess ROS in tumor cells inhibits cancer progression by arresting cancer growth and inducing cell death [84], while CD44-mediated suppression of intracellular ROS has been shown to result in resistance to cancer therapy [85]. Thus, ROS has a double-edged function in cancer. PXDN may contribute to cancer progression by regulating ROS production to low levels.

\section{2. $m i R-29 b-1-5 p$}

Among miRNA, $m i R-29 b-1-5 p$ is attenuated in the expression in triple-negative [86] and basal-like breast cancer [87], whereas it has been reported that overexpression is involved in the acquisition of proliferative ability in bladder cancer [88], and no consensus has been obtained. Laser capture microdissection (LCM) was used to isolate only cancer cells from FFPE specimens of 49 OSCC cases, and then, real-time RT-PCR was performed. The results showed that $m i R-29 b-1-5 p$ was highly expressed in cases showing EMT. Furthermore, miR$29 b-1-5 p$ overexpressing cases had a significantly poorer prognosis than those who did not. EMT is a phenomenon in which the infiltration capacity is strengthened by showing a decrease in the E-cadherin (CDH1) expression involved in cell adhesion and an increase in vimentin (VIM) expression, which is a mesenchymal marker, in cancer [89]. Among OSCC cells, HSC4 cells with EMT-negative phenotype show low expression of miR-29b-1-5p, whereas KON cells with EMT-positive phenotype show high expression of $m i R-29 b-1$ $5 p$. MiR-29b1-5p has a complementary nucleotide sequence to the $3^{\prime}$-UTR of CDH1, and modulation of $m i R-29 b-1-5 p$ expression altered luciferase activity, whereas mutation of the $3^{\prime}$-UTR of CDH1 abolished its function. Additionally, transfection with $m i R-29 b-1-5 p$ resulted in the acquisition of EMT traits such as decreased CDH1 expression and increased VIM expression in HSC4 cells, whereas the repression of $m i R-29 b-1-5 p$ reduced the EMT characteristics in KON cells. These results indicate that miR-29b-1-5p is involved in EMT by targeting CDH1 in OSCC [90].

LCM is a method to collect only the target cells from FFPE specimens and is ideal for studying cancer cell-specific gene expression from biological samples. Nucleic acids in FFPE specimens are highly cross-linked and often degraded, whereas miRNA is a small molecule and is likely to maintain its expression even in FFPE specimens with some long shelf life [91]. Furthermore, as mentioned above, miRNA is thought to be contained in saliva, and a minimally invasive test can be performed by measuring the expression level in saliva. It is a molecule that is greatly expected to be clinically applied to diagnosis and treatment.

\section{Future Perspectives}

Saliva can be an ideal laboratory material for OSCC because it is noninvasive, economical, easy to collect, repeatable, collectible not only by physicians and dentists but also by patients themselves and their families, and can be monitored. Since saliva is in direct contact with OSCC, it is highly anticipated to contain several biomarkers. It has been reported that hypermethylation of tissue inhibitors of metalloproteinase 3 (TIMP3), CDH1, CDKN2A, O-6-methylguanine-DNA methyltransferase (MGMT), death-associated protein kinase $(D A P K)$, and Ras association domain family member 1 (RASSF1) could be detected in salivary DNA of 90 patients with HNSCC [92]. Furthermore, DNA methylation levels of RASSF1, CDKN2A, TIMP3, and mediator complex subunit 15 (MED15) in salivary DNA of HPV-negative HNSCC patients are higher than those of HPV-positive patients and healthy individuals [93]. Exosome analysis in saliva was reported to detect $m i R-302 b$ $3 p$ and $m i R-517 b-3 p$ only in extracellular vesicles of patients with OSCC, suggesting that 
these microRNAs may be useful as metastasis monitoring markers [94]. There are high expectations for the usefulness of saliva as a tool to search for OSCC biomarkers.

Artificial intelligence (AI) is being applied to the field of cancer diagnosis and treatment, and there is no doubt that this trend will accelerate in the future. Toward the clinical application of precision medicine, it is highly expected that new target genetic abnormalities will be discovered by analyzing the vast amount of information accumulated in the database with the maximum use of AI, leading to the development of innovative new drugs and diagnostic methods. With further progress in identifying driver genes for several cancers and developing modalities that can detect gene abnormalities with higher accuracy, it can be asserted that precision medicine will play a central role in cancer medical care in the near future.

\section{Conclusions}

Current pathological diagnosis is based on our predecessors' vast amounts of morphological knowledge. Conversely, it is also true that morphology alone is not enough to face the complex and fragmented pathology of today, and the fields of molecular pathology and genomic pathology will become increasingly important in the future. It is easy to imagine that the morphological changes seen in cancer may largely reflect individual genetic mutations, and future pathologists will be required to have the ability to capture the signals of genetic abnormalities emitted by cancer cells under the microscope. In cancer pathology, morphology and molecules are inseparable. As mentioned above, it is not easy to narrow down the candidates for molecular targets because of the complex effects of several genetic changes during the development, progression, and metastasis of OSCC. Most of the genetic abnormalities that were identified are thought to be passenger mutations that occur incidentally to the development of OSCC, and unfortunately, we have not yet been able to find the driver genes. We have also not yet reached the point of clinical application of molecular diagnosis and treatment targeting these novel factors. However, identifying driver genes is essential for the control of OSCC, and cancer pathologists with an eye for molecules and the ability to diagnose through morphology will play an important role. An understanding of the genetic diversity among individuals and information on genetic alterations (germline and somatic) and epigenetic changes in the process of carcinogenesis and cancer progression is essential to the practice of precision medicine, which determines each patient's optimal treatment. Precision medicine will revolutionize clinical oncology and oncological pathology. Further development of precision medicine in OSCC is expected in the future.

Author Contributions: Conceptualization, T.S. and K.S.; writing-original draft preparation, T.S. and Y.S.; writing - review and editing, T.K.; funding acquisition, T.S. and M.K.-S. All authors have read and agreed to the published version of the manuscript.

Funding: This work was supported in part by Grant-in-Aid for Scientific Research from the Japan Society for the Promotion of Science, Japan (26462790, 17K11621, 18K09796, 20K09912, and 21K10077).

Institutional Review Board Statement: Not applicable.

Informed Consent Statement: Not applicable.

Data Availability Statement: Not applicable.

Conflicts of Interest: The authors declare no conflict of interest.

\section{References}

1. Sung, H.; Ferlay, J.; Siegel, R.L.; Laversanne, M.; Soerjomataram, I.; Jemal, A.; Bray, F. Global cancer statistics 2020: GLOBOCAN estimates of incidence and mortality worldwide for 36 cancers in 185 countries. CA Cancer J. Clin. 2021, 71, 209-249. [CrossRef] [PubMed]

2. Siegel, R.L.; Miller, K.D.; Fuchs, H.E.; Jemal, A. Cancer statistics, 2022. CA Cancer J. Clin. 2022, 72, 7-33. [CrossRef] [PubMed]

3. Patil, R.; Mahajan, A.; Pradeep, G.L.; Prakash, N.; Patil, S.; Khan, S.M. Expression of matrix metalloproteinase-9 in histological grades of oral squamous cell carcinoma: An immunohistochemical study. J. Oral Maxillofac. Pathol. 2021, 25, 239-246. [PubMed] 
4. $\quad$ Rizzo, J.D.; Curtis, R.E.; Socié, G.; Sobocinski, K.A.; Gilbert, E.; Landgren, O.; Travis, L.B.; Travis, W.D.; Flowers, M.E.; Friedman, D.L.; et al. Solid cancers after allogeneic hematopoietic cell transplantation. Blood 2009, 113, 1175-1183. [CrossRef]

5. Hanahan, D.; Weinberg, R.A. Hallmarks of cancer: The next generation. Cell 2011, 144, 646-674. [CrossRef]

6. Sasahira, T.; Kirita, T. Hallmarks of cancer-related newly prognostic factors of oral squamous cell carcinoma. Int. J. Mol. Sci. 2018, 19, 2413. [CrossRef]

7. Kitamura, N.; Sento, S.; Yoshizawa, Y.; Sasabe, E.; Kudo, Y.; Yamamoto, T. Current trends and future prospects of molecular targeted therapy in head and neck squamous cell carcinoma. Int. J. Mol. Sci. 2020, 22, 240. [CrossRef]

8. Akagi, K.; Oki, E.; Taniguchi, H.; Nakatani, K.; Aoki, D.; Kuwata, T.; Yoshino, T. Real-world data on microsatellite instability status in various unresectable or metastatic solid tumors. Cancer Sci. 2021, 112, 1105-1113. [CrossRef]

9. Hause, R.J.; Pritchard, C.C.; Shendure, J.; Salipante, S.J. Classification and characterization of microsatellite instability across 18 cancer types. Nat. Med. 2016, 22, 1342-1350. [CrossRef]

10. Jiang, T.; Wang, G.; Liu, Y.; Feng, L.; Wang, M.; Liu, J.; Chen, Y.; Ouyang, L. Development of small-molecule tropomyosin receptor kinase (TRK) inhibitors for NTRK fusion cancers. Acta Pharm. Sin. B 2021, 11, 355-372. [CrossRef]

11. Sicklick, J.K.; Kato, S.; Okamura, R.; Schwaederle, M.; Hahn, M.E.; Williams, C.B.; De, P.; Krie, A.; Piccioni, D.E.; Miller, V.A.; et al. Molecular profiling of cancer patients enables personalized combination therapy: The I-PREDICT study. Nat. Med. 2019, 25, 744-750. [CrossRef] [PubMed]

12. Kondo, T.; Matsubara, J.; Quy, P.N.; Fukuyama, K.; Nomura, M.; Funakoshi, T.; Doi, K.; Sakamori, Y.; Yoshioka, M.; Yokoyama, A.; et al. Comprehensive genomic profiling for patients with chemotherapy-naïve advanced cancer. Cancer Sci. 2021, 112, 296-304. [CrossRef] [PubMed]

13. Sunami, K.; Ichikawa, H.; Kubo, T.; Kato, M.; Fujiwara, Y.; Shimomura, A.; Koyama, T.; Kakishima, H.; Kitami, M.; Matsushita, H.; et al. Feasibility and utility of a panel testing for 114 cancer-associated genes in a clinical setting: A hospital-based study. Cancer Sci. 2019, 110, 1480-1490. [CrossRef] [PubMed]

14. Sunami, K.; Naito, Y.; Aimono, E.; Amano, T.; Ennishi, D.; Kage, H.; Kanai, M.; Komine, K.; Koyama, T.; Maeda, T.; et al. The initial assessment of expert panel performance in core hospitals for cancer genomic medicine in Japan. Int. J. Clin. Oncol. 2021, 26, 443-449. [CrossRef] [PubMed]

15. Network, C.G.A. Comprehensive genomic characterization of head and neck squamous cell carcinomas. Nature 2015, 517, 576-582. [CrossRef]

16. Baumeister, P.; Reiter, M.; Welz, C.; Becker, S.; Betz, C.; Harréus, U. Surgically treated oropharyngeal cancer: Risk factors and tumor characteristics. J. Cancer Res. Clin. Oncol. 2014, 140, 1011-1019. [CrossRef]

17. Bonner, J.A.; Harari, P.M.; Giralt, J.; Cohen, R.B.; Jones, C.U.; Sur, R.K.; Raben, D.; Baselga, J.; Spencer, S.A.; Zhu, J.; et al. Radiotherapy plus cetuximab for locoregionally advanced head and neck cancer: 5 -year survival data from a phase 3 randomised trial, and relation between cetuximab-induced rash and survival. Lancet Oncol. 2010, 11, 21-28. [CrossRef]

18. Gillison, M.L.; Trotti, A.M.; Harris, J.; Eisbruch, A.; Harari, P.M.; Adelstein, D.J.; Jordan, R.C.K.; Zhao, W.; Sturgis, E.M.; Burtness, B.; et al. Radiotherapy plus cetuximab or cisplatin in human papillomavirus-positive oropharyngeal cancer (NRG Oncology RTOG 1016): A randomised, multicentre, non-inferiority trial. Lancet 2019, 393, 40-50. [CrossRef]

19. Saito, Y.; Hayashi, R.; Iida, Y.; Mizumachi, T.; Fujii, T.; Matsumoto, F.; Beppu, T.; Yoshida, M.; Shinomiya, H.; Kamiyama, R.; et al Optimization of therapeutic strategy for p16-positive oropharyngeal squamous cell carcinoma: Multi-institutional observational study based on the national Head and Neck Cancer Registry of Japan. Cancer 2020, 126, 4177-4187. [CrossRef]

20. Walter, V.; Yin, X.; Wilkerson, M.D.; Cabanski, C.R.; Zhao, N.; Du, Y.; Ang, M.K.; Hayward, M.C.; Salazar, A.H.; Hoadley, K.A.; et al. Molecular subtypes in head and neck cancer exhibit distinct patterns of chromosomal gain and loss of canonical cancer genes. PLOS ONE 2013, 8, e56823. [CrossRef]

21. Keck, M.K.; Zuo, Z.; Khattri, A.; Stricker, T.P.; Brown, C.D.; Imanguli, M.; Rieke, D.; Endhardt, K.; Fang, P.; Brägelmann, J.; et al. Integrative analysis of head and neck cancer identifies two biologically distinct HPV and three non-HPV subtypes. Clin. Cancer Res. 2015, 21, 870-881. [CrossRef] [PubMed]

22. Puram, S.V.; Tirosh, I.; Parikh, A.S.; Patel, A.P.; Yizhak, K.; Gillespie, S.; Rodman, C.; Luo, C.L.; Mroz, E.A.; Emerick, K.S.; et al. Single-Cell Transcriptomic Analysis of Primary and Metastatic Tumor Ecosystems in Head and Neck Cancer. Cell 2017, 171, 1611-1624.e24. [CrossRef] [PubMed]

23. Huang, L.; David, O.; Cabay, R.J.; Valyi-Nagy, K.; Macias, V.; Zhong, R.; Wenig, B.; Feldman, L.; Weichselbaum, R.; Spiotto, M.T. Molecular classification of lymph node metastases subtypes predict for survival in head and neck cancer. Clin. Cancer Res. 2019, 25, 1795-1808. [CrossRef] [PubMed]

24. Sasahira, T.; Kurihara, M.; Nakashima, C.; Kirita, T.; Kuniyasu, H. LEM domain containing 1 promotes oral squamous cell carcinoma invasion and endothelial transmigration. Br. J. Cancer 2016, 115, 52-58. [CrossRef]

25. Wu, J.Y.; Yi, C.; Chung, H.R.; Wang, D.J.; Chang, W.C.; Lee, S.Y.; Lin, C.T.; Yang, Y.C.; Yang, W.C. Potential biomarkers in saliva for oral squamous cell carcinoma. Oral Oncol. 2010, 46, 226-231. [CrossRef] [PubMed]

26. Wan, J.C.M.; Massie, C.; Garcia-Corbacho, J.; Mouliere, F.; Brenton, J.D.; Caldas, C.; Pacey, S.; Baird, R.; Rosenfeld, N. Liquid biopsies come of age: Towards implementation of circulating tumour DNA. Nat. Rev. Cancer 2017, 17, 223-238. [CrossRef] [PubMed] 
27. Zviran, A.; Schulman, R.C.; Shah, M.; Hill, S.T.K.; Deochand, S.; Khamnei, C.C.; Maloney, D.; Patel, K.; Liao, W.; Widman, A.J.; et al. Genome-wide cell-free DNA mutational integration enables ultra-sensitive cancer monitoring. Nat. Med. 2020, 26, 1114-1124. [CrossRef]

28. Corcoran, R.B.; Chabner, B.A. Application of cell-free DNA analysis to cancer treatment. N. Engl. J. Med. 2018, $379,1754-1765$. [CrossRef]

29. Baby, N.T.; Abdullah, A.; Kannan, S. The scope of liquid biopsy in the clinical management of oral cancer. Int. J. Oral Maxillofac. Surg. 2021, in press. [CrossRef]

30. Perdomo, S.; Avogbe, P.H.; Foll, M.; Abedi-Ardekani, B.; Facciolla, V.L.; Anantharaman, D.; Chopard, P.; Calvez-Kelm, F.L.; Vilensky, M.; Polesel, J.; et al. Circulating tumor DNA detection in head and neck cancer: Evaluation of two different detection approaches. Oncotarget 2017, 8, 72621-72632. [CrossRef]

31. Schröck, A.; Leisse, A.; de Vos, L.; Gevensleben, H.; Dröge, F.; Franzen, A.; Wachendörfer, M.; Schröck, F.; Ellinger, J.; Teschke, M.; et al. Free-circulating methylated DNA in blood for diagnosis, staging, prognosis, and monitoring of head and neck squamous cell carcinoma patients: An observational prospective cohort study. Clin. Chem. 2017, 63, 1288-1296. [CrossRef] [PubMed]

32. Lousada-Fernandez, F.; Rapado-Gonzalez, O.; Lopez-Cedrun, J.L.; Lopez-Lopez, R.; Muinelo-Romay, L.; Suarez-Cunqueiro, M.M. Liquid biopsy in oral cancer. Int. J. Mol. Sci. 2018, 19, 1704. [CrossRef] [PubMed]

33. Hristozova, T.; Konschak, R.; Stromberger, C.; Fusi, A.; Liu, Z.; Weichert, W.; Stenzinger, A.; Budach, V.; Keilholz, U.; Tinhofer, I The presence of circulating tumor cells (CTCs) correlates with lymph node metastasis in nonresectable squamous cell carcinoma of the head and neck region (SCCHN). Ann. Oncol. 2011, 22, 1878-1885. [CrossRef] [PubMed]

34. Oliveira-Costa, J.P.; de Carvalho, A.F.; da Silveira, G.G.; Amaya, P.; Wu, Y.; Park, K.J.; Gigliola, M.P.; Lustberg, M.; Buim, M.E.; Ferreira, E.N.; et al. Gene expression patterns through oral squamous cell carcinoma development: PD-L1 expression in primary tumor and circulating tumor cells. Oncotarget 2015, 6, 20902-20920. [CrossRef]

35. Wang, H.M.; Wu, M.H.; Chang, P.H.; Lin, H.C.; Liao, C.D.; Wu, S.M.; Hung, T.M.; Lin, C.Y.; Chang, T.C.; Tzu-Tsen, Y.; et al. The change in circulating tumor cells before and during concurrent chemoradiotherapy is associated with survival in patients with locally advanced head and neck cancer. Head Neck 2019, 41, 2676-2687. [CrossRef]

36. Tada, H.; Takahashi, H.; Kawabata-Iwakawa, R.; Nagata, Y.; Uchida, M.; Shino, M.; Ida, S.; Mito, I.; Matsuyama, T.; Chikamatsu, K. Molecular phenotypes of circulating tumor cells and efficacy of nivolumab treatment in patients with head and neck squamous cell carcinoma. Sci. Rep. 2020, 10, 21573. [CrossRef]

37. Grisanti, S.; Almici, C.; Consoli, F.; Buglione, M.; Verardi, R.; Bolzoni-Villaret, A.; Bianchetti, A.; Ciccarese, C.; Mangoni, M.; Ferrari, L.; et al. Circulating tumor cells in patients with recurrent or metastatic head and neck carcinoma: Prognostic and predictive significance. PLoS ONE 2014, 9, e103918. [CrossRef]

38. Miyamoto, D.T.; Zheng, Y.; Wittner, B.S.; Lee, R.J.; Zhu, H.; Broderick, K.T.; Desai, R.; Fox, D.B.; Brannigan, B.W.; Trautwein, J.; et al. RNA-Seq of single prostate CTCs implicates noncanonical Wnt signaling in antiandrogen resistance. Science 2015, 349, 1351-1356. [CrossRef]

39. Rupaimoole, R.; Slack, F.J. MicroRNA therapeutics: Towards a new era for the management of cancer and other diseases. Nat. Rev. Drug Discov. 2017, 16, 203-222. [CrossRef]

40. Rabinowits, G.; Bowden, M.; Flores, L.M.; Verselis, S.; Vergara, V.; Jo, V.Y.; Chau, N.; Lorch, J.; Hammerman, P.S.; Thomas, T.; et al. Comparative analysis of microRNA expression among benign and malignant tongue tissue and plasma of patients with tongue cancer. Front. Oncol. 2017, 7, 191. [CrossRef]

41. Arndt, S.; Bosserhoff, A.K. TANGO is a tumor suppressor of malignant melanoma. Int. J. Cancer 2006, 119, 2812-2820. [CrossRef] [PubMed]

42. Arndt, S.; Bosserhoff, A.K. Reduced expression of TANGO in colon and hepatocellular carcinomas. Oncol. Rep. 2007, 18, 885-891. [CrossRef] [PubMed]

43. Stoll, R.; Bosserhoff, A. Extracellular SH3 domain containing proteins-features of a new protein family. Curr. Protein Pept. Sci. 2008, 9, 221-226. [CrossRef] [PubMed]

44. Arndt, S.; Melle, C.; Mondal, K.; Klein, G.; von Eggeling, F.; Bosserhoff, A.K. Interactions of TANGO and leukocyte integrin CD11c/CD18 regulate the migration of human monocytes. J. Leukoc. Biol. 2007, 82, 1466-1472. [CrossRef]

45. Sasahira, T.; Kirita, T.; Yamamoto, K.; Ueda, N.; Kurihara, M.; Matsushima, S.; Bhawal, U.K.; Bosserhoff, A.K.; Kuniyasu, H. Transport and Golgi organisation protein 1 is a novel tumour progressive factor in oral squamous cell carcinoma. Eur. J. Cancer 2014, 50, 2142-2151. [CrossRef]

46. Sasahira, T.; Bosserhoff, A.K.; Kirita, T. The importance of melanoma inhibitory activity gene family in the tumor progression of oral cancer. Pathol. Int. 2018, 68, 278-286. [CrossRef]

47. Sasahira, T.; Kurihara-Shimomura, M.; Shimomura, H.; Bosserhoff, A.K.; Kirita, T. Identification of oral squamous cell carcinoma markers MUC2 and SPRR1B downstream of TANGO. J. Cancer Res. Clin. Oncol. 2021, 147, 1659-1672. [CrossRef]

48. Xiao, X.; Wang, L.; Wei, P.; Chi, Y.; Li, D.; Wang, Q.; Ni, S.; Tan, C.; Sheng, W.; Sun, M.; et al. Role of MUC20 overexpression as a predictor of recurrence and poor outcome in colorectal cancer. J. Transl. Med. 2013, 11, 151. [CrossRef]

49. Chen, S.T.; Kuo, T.C.; Liao, Y.Y.; Lin, M.C.; Tien, Y.W.; Huang, M.C. Silencing of MUC20 suppresses the malignant character of pancreatic ductal adenocarcinoma cells through inhibition of the HGF/MET pathway. Oncogene 2018, 37, 6041-6053. [CrossRef] 
50. Chen, C.H.; Shyu, M.K.; Wang, S.W.; Chou, C.H.; Huang, M.J.; Lin, T.C.; Chen, S.T.; Lin, H.H.; Huang, M.C. MUC20 promotes aggressive phenotypes of epithelial ovarian cancer cells via activation of the integrin $\beta 1$ pathway. Gynecol. Oncol. 2016, 140, 131-137. [CrossRef]

51. Shen, L.Y.; Wang, H.; Dong, B.; Yan, W.P.; Lin, Y.; Shi, Q.; Chen, K.N. Possible prediction of the response of esophageal squamous cell carcinoma to neoadjuvant chemotherapy based on gene expression profiling. Oncotarget 2016, 7, 4531-4541. [CrossRef] [PubMed]

52. Fujimoto, W.; Nakanishi, G.; Arata, J.; Jetten, A.M. Differential expression of human cornifin alpha and beta in squamous differentiating epithelial tissues and several skin lesions. J. Investig. Dermatol. 1997, 108, 200-204. [CrossRef] [PubMed]

53. Reddy, S.P.; Vuong, H.; Adiseshaiah, P. Interplay between proximal and distal promoter elements is required for squamous differentiation marker induction in the bronchial epithelium: Role for ESE-1, Sp1, and AP-1 proteins. J. Biol. Chem. 2003, 278, 21378-21387. [CrossRef] [PubMed]

54. Hippo, Y.; Yashiro, M.; Ishii, M.; Taniguchi, H.; Tsutsumi, S.; Hirakawa, K.; Kodama, T.; Aburatani, H. Differential gene expression profiles of scirrhous gastric cancer cells with high metastatic potential to peritoneum or lymph nodes. Cancer Res. 2001, 61, 889-895. [PubMed]

55. Ludovini, V.; Bianconi, F.; Siggillino, A.; Piobbico, D.; Vannucci, J.; Metro, G.; Chiari, R.; Bellezza, G.; Puma, F.; Della Fazia, M.A.; et al. Gene identification for risk of relapse in stage I lung adenocarcinoma patients: A combined methodology of gene expression profiling and computational gene network analysis. Oncotarget 2016, 7, 30561-30574. [CrossRef]

56. Li, W.; Nadelman, C.; Henry, G.; Fan, J.; Muellenhoff, M.; Medina, E.; Gratch, N.S.; Chen, M.; Han, J.; Woodley, D. The p38MAPK/SAPK pathway is required for human keratinocyte migration on dermal collagen. J. Investig. Dermatol. 2001, 117, 1601-1611. [CrossRef]

57. Cho, K.H.; Son, Y.S.; Lee, D.Y.; Chung, E.K.; Hur, K.C.; Hong, S.I.; Fuchs, E. Calcipotriol (MC 903), a synthetic derivative of vitamin D3 stimulates differentiation of squamous carcinoma cell line in the raft culture. Anticancer Res. 1996, 16, 337-347.

58. Yuki, D.; Lin, Y.M.; Fujii, Y.; Nakamura, Y.; Furukawa, Y. Isolation of LEM domain-containing 1, a novel testis-specific gene expressed in colorectal cancers. Oncol. Rep. 2004, 12, 275-280. [CrossRef]

59. Gjerstorff, M.F.; Andersen, M.H.; Ditzel, H.J. Oncogenic cancer/testis antigens: Prime candidates for immunotherapy. Oncotarget 2015, 6, 15772-15787. [CrossRef]

60. Sia, G.M.; Clem, R.L.; Huganir, R.L. The human language-associated gene SRPX2 regulates synapse formation and vocalization in mice. Science 2013, 342, 987-991. [CrossRef]

61. Tanaka, K.; Arao, T.; Tamura, D.; Aomatsu, K.; Furuta, K.; Matsumoto, K.; Kaneda, H.; Kudo, K.; Fujita, Y.; Kimura, H.; et al. SRPX2 is a novel chondroitin sulfate proteoglycan that is overexpressed in gastrointestinal cancer. PLoS ONE 2012, 7, e27922. [CrossRef] [PubMed]

62. Øster, B.; Linnet, L.; Christensen, L.L.; Thorsen, K.; Ongen, H.; Dermitzakis, E.T.; Sandoval, J.; Moran, S.; Esteller, M.; Hansen, T.F.; et al. Non-CpG island promoter hypomethylation and miR-149 regulate the expression of SRPX2 in colorectal cancer. Int. J. Cancer 2013, 132, 2303-2315. [CrossRef] [PubMed]

63. Li, H.; Zhang, S.R.; Xu, H.X.; Wang, W.Q.; Li, S.; Li, T.J.; Ni, Q.X.; Yu, X.J.; Liu, L.; Wu, C.T. SRPX2 and RAB31 are effective prognostic biomarkers in pancreatic cancer. J. Cancer 2019, 10, 2670-2678. [CrossRef] [PubMed]

64. Sasahira, T.; Kurihara-Shimomura, M.; Nishiguchi, Y.; Shimomura, H.; Kirita, T. Sushi repeat containing protein X-linked 2 is a downstream signal of LEM domain containing 1 and acts as a tumor-promoting factor in oral squamous cell carcinoma. Int. J. Mol. Sci. 2020, 21, 3655. [CrossRef]

65. Miljkovic-Licina, M.; Hammel, P.; Garrido-Urbani, S.; Bradfield, P.F.; Szepetowski, P.; Imhof, B.A. Sushi repeat protein X-linked 2, a novel mediator of angiogenesis. FASEB J. 2009, 23, 4105-4116. [CrossRef]

66. Sun, W.; Lv, W.; Lv, H.; Zhang, R.; Jiang, Y. Genome-wide haplotype association analysis identifies SERPINB9, SERPINE2, GAK, and HSP90B1 as novel risk genes for oral squamous cell carcinoma. Tumour Biol. 2016, 37, 1845-1851. [CrossRef]

67. Xu, D.; McKee, C.M.; Cao, Y.; Ding, Y.; Kessler, B.M.; Muschel, R.J. Matrix metalloproteinase-9 regulates tumor cell invasion through cleavage of protease nexin-1. Cancer Res. 2010, 70, 6988-6998. [CrossRef]

68. McKee, C.M.; Xu, D.; Cao, Y.; Kabraji, S.; Allen, D.; Kersemans, V.; Beech, J.; Smart, S.; Hamdy, F.; Ishkanian, A.; et al. Protease nexin 1 inhibits hedgehog signaling in prostate adenocarcinoma. J. Clin. Investig. 2012, 122, 4025-4036. [CrossRef]

69. Pagliara, V.; Adornetto, A.; Mammì, M.; Masullo, M.; Sarnataro, D.; Pietropaolo, C.; Arcone, R. Protease nexin-1 affects the migration and invasion of $\mathrm{C} 6$ glioma cells through the regulation of urokinase plasminogen activator and matrix metalloproteinase9/2. Biochim. Biophys. Acta 2014, 1843, 2631-2644. [CrossRef]

70. Sasahira, T.; Kurihara-Shimomura, M.; Shimomura, H.; Kirita, T. SERPINE2 is an oral cancer-promoting factor that induces angiogenesis and lymphangiogenesis. Int. J. Clin. Oncol. 2021, 26, 1831-1839. [CrossRef]

71. Sasahira, T.; Kirita, T.; Kurihara, M.; Yamamoto, K.; Bhawal, U.K.; Bosserhoff, A.K.; Kuniyasu, H. MIA-dependent angiogenesis and lymphangiogenesis are closely associated with progression, nodal metastasis and poor prognosis in tongue squamous cell carcinoma. Eur. J. Cancer 2010, 46, 2285-2294. [CrossRef]

72. Kerbel, R.S. Tumor angiogenesis. N. Engl. J. Med. 2008, 358, 2039-2049. [CrossRef] [PubMed]

73. Mpekris, F.; Baish, J.W.; Stylianopoulos, T.; Jain, R.K. Role of vascular normalization in benefit from metronomic chemotherapy. Proc. Natl. Acad. Sci. USA 2017, 114, 1994-1999. [CrossRef] [PubMed] 
74. Voutouri, C.; Kirkpatrick, N.D.; Chung, E.; Mpekris, F.; Baish, J.W.; Munn, L.L.; Fukumura, D.; Stylianopoulos, T.; Jain, R.K. Experimental and computational analyses reveal dynamics of tumor vessel cooption and optimal treatment strategies. Proc. Natl. Acad. Sci. USA 2019, 116, 2662-2671. [CrossRef] [PubMed]

75. Yang, L.; Zhang, W.; Wang, Y.; Zou, T.; Zhang, B.; Xu, Y.; Pang, T.; Hu, Q.; Chen, M.; Wang, L.; et al. Hypoxia-induced miR-214 expression promotes tumour cell proliferation and migration by enhancing the Warburg effect in gastric carcinoma cells. Cancer Lett. 2018, 414, 44-56. [CrossRef]

76. Dougan, J.; Hawsawi, O.; Burton, L.J.; Edwards, G.; Jones, K.; Zou, J.; Nagappan, P.; Wang, G.; Zhang, Q.; Danaher, A.; et al Proteomics-metabolomics combined approach identifies peroxidasin as a protector against metabolic and oxidative stress in prostate cancer. Int. J. Mol. Sci. 2019, 20, 3046. [CrossRef]

77. Cai, X.; Yang, X.; Jin, C.; Li, L.; Cui, Q.; Guo, Y.; Dong, Y.; Yang, X.; Guo, L.; Zhang, M. Identification and verification of differentially expressed microRNAs and their target genes for the diagnosis of esophageal cancer. Oncol. Lett. 2018, 16, 3642-3650. [CrossRef]

78. Zheng, Y.Z.; Liang, L. High expression of PXDN is associated with poor prognosis and promotes proliferation, invasion as well as migration in ovarian cancer. Ann. Diagn. Pathol. 2018, 34, 161-165. [CrossRef]

79. Kurihara-Shimomura, M.; Sasahira, T.; Shimomura, H.; Kirita, T. Peroxidan plays a tumor-promoting role in oral squamous cell carcinoma. Int. J. Mol. Sci. 2020, 21, 5416. [CrossRef]

80. Kon, S.; Ishibashi, K.; Katoh, H.; Kitamoto, S.; Shirai, T.; Tanaka, S.; Kajita, M.; Ishikawa, S.; Yamauchi, H.; Yako, Y.; et al. Cell competition with normal epithelial cells promotes apical extrusion of transformed cells through metabolic changes. Nat. Cell Biol. 2017, 19, 530-541. [CrossRef]

81. Gao, P.; Zhang, H.; Dinavahi, R.; Li, F.; Xiang, Y.; Raman, V.; Bhujwalla, Z.M.; Felsher, D.W.; Cheng, L.; Pevsner, J.; et al HIF-dependent antitumorigenic effect of antioxidants in vivo. Cancer Cell 2007, 12, 230-238. [CrossRef] [PubMed]

82. Klein, E.A.; Thompson, I.M., Jr.; Tangen, C.M.; Crowley, J.J.; Lucia, M.S.; Goodman, P.J.; Minasian, L.M.; Ford, L.G.; Parnes, H.L.; Gaziano, J.M.; et al. Vitamin E and the risk of prostate cancer: The Selenium and Vitamin E Cancer Prevention Trial (SELECT). JAMA 2011, 306, 1549-1556. [CrossRef] [PubMed]

83. Chandel, N.S.; Tuveson, D.A. The promise and perils of antioxidants for cancer patients. N. Engl. J. Med. 2014, 371, 177-178. [CrossRef]

84. Piskounova, E.; Agathocleous, M.; Murphy, M.M.; Hu, Z.; Huddlestun, S.E.; Zhao, Z.; Leitch, A.M.; Johnson, T.M.; DeBerardinis, R.J.; Morrison, S.J. Oxidative stress inhibits distant metastasis by human melanoma cells. Nature 2015, 527, 186-191. [CrossRef] [PubMed]

85. Ishimoto, T.; Nagano, O.; Yae, T.; Tamada, M.; Motohara, T.; Oshima, H.; Oshima, M.; Ikeda, T.; Asaba, R.; Yagi, H.; et al. CD44 variant regulates redox status in cancer cells by stabilizing the $\mathrm{xCT}$ subunit of system $\mathrm{xc}(-)$ and thereby promotes tumor growth. Cancer Cell 2011, 19, 387-400. [CrossRef]

86. Drago-Ferrante, R.; Pentimalli, F.; Carlisi, D.; De Blasio, A.; Saliba, C.; Baldacchino, S.; Degaetano, J.; Debono, J.; Caruana-Dingli, G.; Grech, G.; et al. Suppressive role exerted by microRNA-29b-1-5p in triple negative breast cancer through SPIN1 regulation. Oncotarget 2017, 8, 28939-28958. [CrossRef]

87. Milevskiy, M.J.G.; Sandhu, G.K.; Wronski, A.; Korbie, D.; Brewster, B.L.; Shewan, A.; Edwards, S.L.; French, J.D.; Brown, M.A MiR-29b-1-5p is altered in BRCA1 mutant tumours and is a biomarker in basal-like breast cancer. Oncotarget 2018, 9, 33577-33588. [CrossRef] [PubMed]

88. Xu, F.; Zhang, Q.; Cheng, W.; Zhang, Z.; Wang, J.; Ge, J. Effect of miR-29b-1* and miR-29c knockdown on cell growth of the bladder cancer cell line T24. J. Int. Med. Res. 2013, 41, 1803-1810. [CrossRef] [PubMed]

89. Mak, M.P.; Tong, P.; Diao, L.; Cardnell, R.J.; Gibbons, D.L.; William, W.N.; Skoulidis, F.; Parra, E.R.; Rodriguez-Canales, J.; Wistuba, I.I.; et al. A Patient-derived, pan-cancer EMT signature identifies global molecular alterations and immune target enrichment following epithelial-to-mesenchymal transition. Clin. Cancer Res. 2016, 22, 609-620. [CrossRef]

90. Kurihara-Shimomura, M.; Sasahira, T.; Shimomura, H.; Nakashima, C.; Kirita, T. The oncogenic activity of miR-29b-1-5p induces the epithelial-mesenchymal transition in oral squamous cell carcinoma. J. Clin. Med. 2019, 8, 273. [CrossRef]

91. Sasahira, T.; Kurihara, M.; Bhawal, U.K.; Ueda, N.; Shimomoto, T.; Yamamoto, K.; Kirita, T.; Kuniyasu, H. Downregulation of miR-126 induces angiogenesis and lymphangiogenesis by activation of VEGF-A in oral cancer. Br. J. Cancer 2012, 107, 700-706. [CrossRef] [PubMed]

92. Righini, C.A.; de Fraipont, F.; Timsit, J.F.; Faure, C.; Brambilla, E.; Reyt, E.; Favrot, M.C. Tumor-specific methylation in saliva: A promising biomarker for early detection of head and neck cancer recurrence. Clin. Cancer Res. 2007, 13, 1179-1185. [CrossRef] [PubMed]

93. Lim, Y.; Wan, Y.; Vagenas, D.; Ovchinnikov, D.A.; Perry, C.F.; Davis, M.J.; Punyadeera, C. Salivary DNA methylation panel to diagnose HPV-positive and HPV-negative head and neck cancers. BMC Cancer 2016, 16, 749. [CrossRef] [PubMed]

94. Gai, C.; Camussi, F.; Broccoletti, R.; Gambino, A.; Cabras, M.; Molinaro, L.; Carossa, S.; Camussi, G.; Arduino, P.G. Salivary extracellular vesicle-associated miRNAs as potential biomarkers in oral squamous cell carcinoma. BMC Cancer 2018, 18, 439. [CrossRef] 